\title{
Expression of ATF3 and axonal outgrowth are impaired after delayed nerve repair Harukazu Saito ${ }^{1}$ and Lars B Dahlin*2
}

Address: ${ }^{1}$ Department of Orthopaedic Surgery, School of Medicine, Keio University, Tokyo, Japan and ${ }^{2}$ Department of Hand Surgery, Malmö University Hospital, Malmö, Sweden

Email: Harukazu Saito - haruka-z@fa2.so-net.ne.jp; Lars B Dahlin* - lars.dahlin@med.lu.se

* Corresponding author

Published: 18 September 2008

BMC Neuroscience 2008, 9:88 doi:10.1/86//47|-2202-9-88
Received: 26 March 2008

Accepted: 18 September 2008

This article is available from: http://www.biomedcentral.com/I47I-2202/9/88

(c) 2008 Saito and Dahlin; licensee BioMed Central Ltd.

This is an Open Access article distributed under the terms of the Creative Commons Attribution License (http://creativecommons.org/licenses/by/2.0), which permits unrestricted use, distribution, and reproduction in any medium, provided the original work is properly cited.

\begin{abstract}
Background: A delay in surgical nerve repair results in impaired nerve function in humans, but mechanisms behind the weakened nerve regeneration are not known. Activating transcription factor 3 (ATF3) increases the intrinsic growth state of injured neurons early after injury, but the role of long-term changes and their relation to axonal outgrowth after a delayed nerve repair are not well understood. ATF3 expression was examined by immunohistochemistry in motor and sensory neurons and in Schwann cells in rat sciatic nerve and related to axonal outgrowth after transection and delayed nerve repair (repair $0,30,90$ or 180 days post-injury). Expression of the neuronal cell adhesion molecule (NCAM), which is expressed in non-myelinating Schwann cells, was also examined.

Results: The number of neurons and Schwann cells expressing ATF3 declined and the length of axonal outgrowth was impaired if the repair was delayed. The decline was more rapid in motor neurons than in sensory neurons and Schwann cells. Regeneration distances over time correlated to number of ATF3 stained neurons and Schwann cells. Many neurofilament stained axons grew along ATF3 stained Schwann cells. If nerve repair was delayed the majority of Schwann cells in the distal nerve segment stained for NCAM.

Conclusion: Delayed nerve repair impairs nerve regeneration and length of axonal outgrowth correlates to ATF3 expression in both neurons and Schwann cells. Mainly non-myelinating Schwann cells (NCAM stained) are present in distal nerve segments after delayed nerve repair. These data provide a neurobiological basis for the poor outcomes associated with delayed nerve repair. Nerve trunks should, if possible, be promptly repaired.
\end{abstract}

\section{Background}

Impaired nerve regeneration and weakened target reinnervation are significant clinical problems after nerve injury when the repair of a nerve trunk is delayed [1-3]. Clinically, recovery of motor function is also less than sensory recovery after delayed repair [4], possibly due to the outgrowth of sensory axons interfering with the outgrowth of motor axons $[5,6]$. In delayed nerve repair the previously injured neurons are reactivated upon the additional injury leading to axonal outgrowth [7]. After a nerve injury Schwann cells are rapidly activated at site of the lesion [8] and in the distal nerve segment with proliferation and remodelling of the extracellular matrix [9]. The insufficient nerve regeneration after delayed nerve repair has 
been attributed to an inability of Schwann cells to support axonal outgrowth $[10,11]$. However, detailed signal transduction mechanisms underlying the impaired nerve regeneration are not well understood.

Activating transcription factor 3 (ATF3) is rapidly expressed in neurons and Schwann cells after injury and is preceeded by phosphorylation of c-Jun and JNK activation [12-15]. The number of Schwann cells and neurons in the spinal cord that express ATF3 declines over time if nerve regeneration is prevented $[14,16,17]$, although some sensory neurons may express ATF3 for at least 140 days after injury [16]. A nerve repair 30 days after injury leads to a reduction in the number of ATF3 stained Schwann cells in the distal nerve [14]. However, the consequences of ATF3 expression in neurons and Schwann cells for axonal outgrowth in relation to time after nerve injury are not known, particularly if there is a time limit at which a delayed nerve repair can be performed. In addition, the neural cell adhesion molecule (NCAM) is expressed mainly in non-myelinating Schwann cells [18], but its alteration after delayed nerve repair is unknown. Our aim was to study ATF3 expression in neurons and Schwann cells and relate that to axonal outgrowth and the presence of NCAM, after delayed nerve repair.

\section{Results}

Nerve transection and repair induced expression of ATF3 in motor and sensory neurons and in non-neuronal cells (i.e. Schwann cells; see below) at the site of the lesion and in the distal nerve segment (Figure 1 and 2). The number of neurons and Schwann cells that stained for ATF3 are

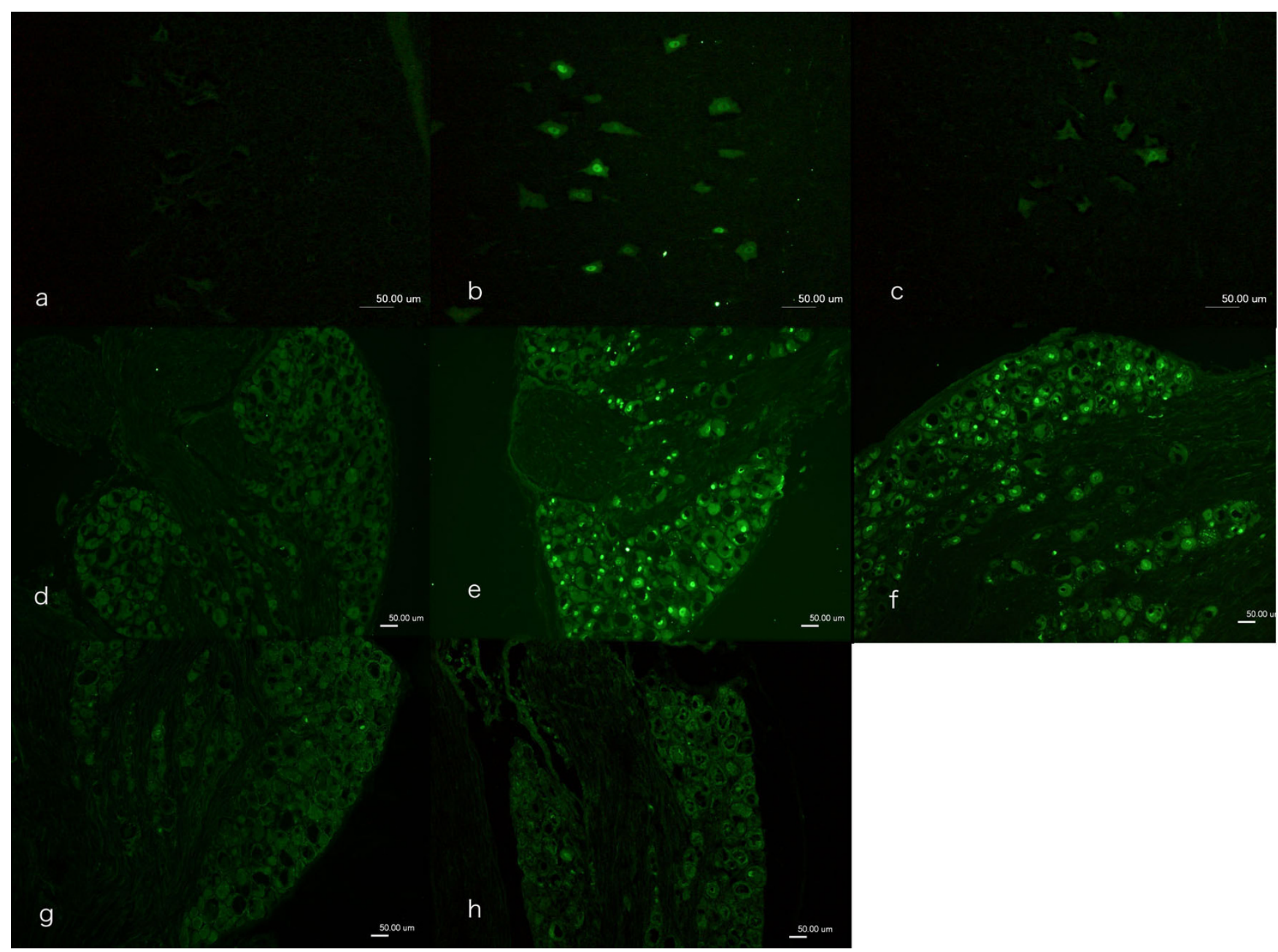

Figure I

Immunocytochemical staining of ATF3 in motor neurons in spinal cord (a-c) and in sensory neurons in DRG (d-h). In the contralateral side ( $a, d)$ no ATF3 stained neurons were observed. ATF3 stained neurons were observed where the sciatic nerve was transected and repaired immediately (day 0, b, e), after 30 days (c, f), after 90 days ( $\mathrm{g}$ ) and after 180 days (h). Scale bar $=50 \mu \mathrm{m}$. 

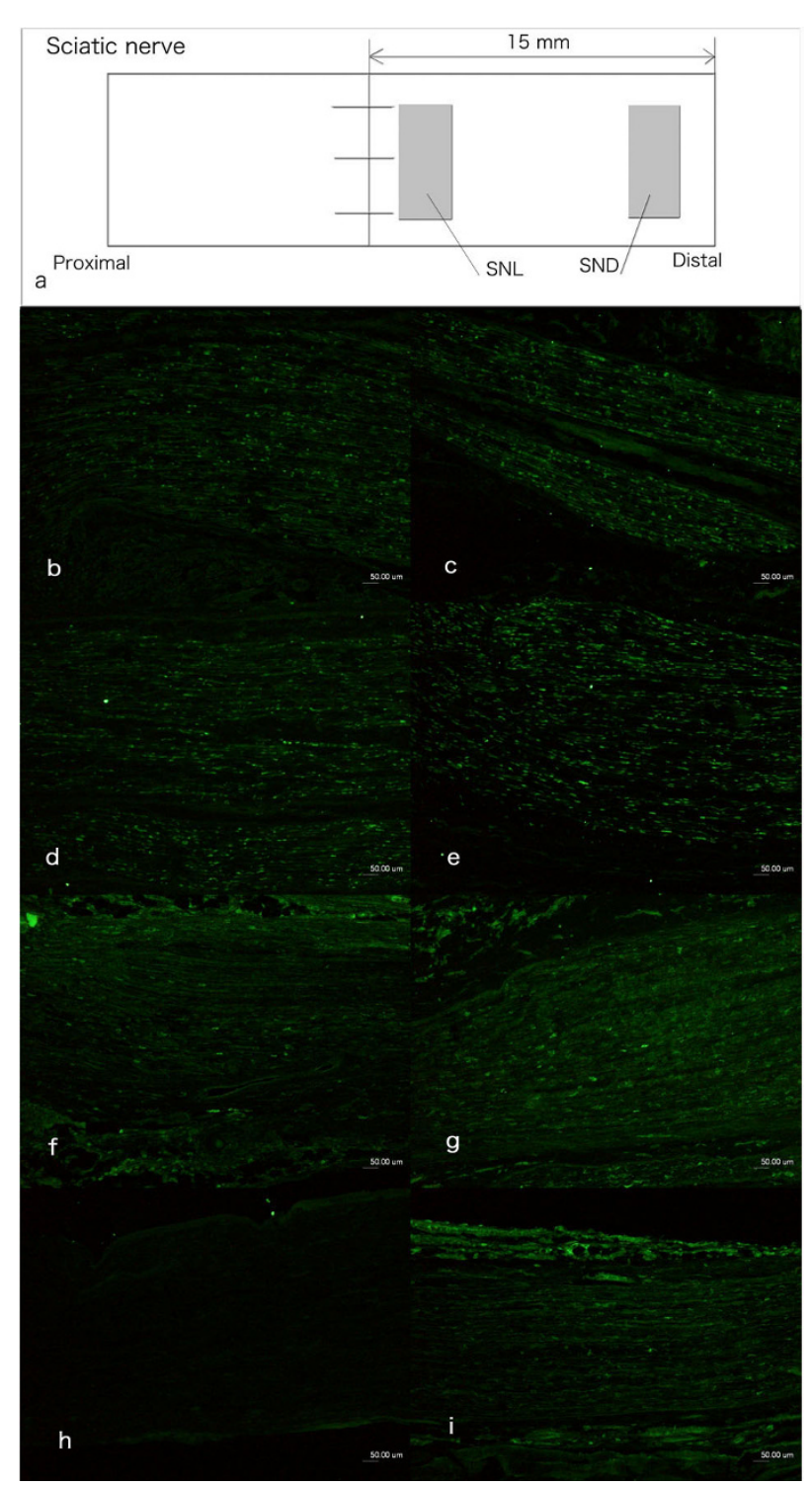

\section{Figure 2}

Immunocytochemical staining of ATF3 in non-neuronal cells in the sciatic nerve. The non-neuronal cells were interpreted to be mainly Schwann cells based on the shape of the nucleus and location within basal lamina (also stained for $\mathrm{S}-100)$. The schematic drawing in (a) showed the sites where ATF3 stained cells were analysed in sciatic nerve of rats. SNL: distal site adjacent to the sutured lesion; SND: $15 \mathrm{~mm}$ distal to the sutured lesion. The number of cells was also calculated $15 \mathrm{~mm}$ proximal to and at the proximal site of the sutured lesion (results not shown). The photos on the left column (b, $d, f$ ) are from the site of lesion (SNL) and in the right column are from the distal nerve segment (SND; c, e, g, i) where the sciatic nerve was immediately repaired (b, c), repair after 30 days $(\mathrm{d}, \mathrm{e}), 90$ days ( $\mathrm{f}, \mathrm{g}$ ) and 180 days (i). The contralateral uninjured sciatic nerve showed no or single ATF3 stained cells $(\mathrm{h})$. Scale bar $=50 \mu \mathrm{m}$. summarised in Table 1 [see Additional file 1]. Generally, a significantly (Mann-Whitney; $\mathrm{p}<0.005$ ) higher number of ATF3 stained neurons and Schwann cells were present on the experimental side compared to contralateral, noninjured, side at all time points (result not shown) except: 1) number of ATF3 stained Schwann cells in the segment $15 \mathrm{~mm}$ proximal to the lesion were not different (result not shown); 2) number of motor neurons in the groups where the sciatic nerve was repaired with a delay of 90 and 180 days. Furthermore, the total number of DAPI stained cells was higher at the experimental sides (distal nerve segment, site of lesion and $15 \mathrm{~mm}$ proximal to site of lesion) than in the contralateral nerve at all time points except in the proximal nerve segment ( $15 \mathrm{~mm}$ proximal to suture) after immediate repair.

\begin{abstract}
Neurons
Motor neurons in spinal cord

In the contralateral uninjured side, no ATF3 stained motor neurons were observed (Figure 1a). The number of motor neurons that expressed ATF3 declined over time, where ATF3 stained neurons were mainly observed after immediate repair and to a less number when the sciatic nerve was repaired at 30 days or later (Fig. 1b and 1c). Statistical analyses showed a difference between the groups (Kruskal Wallis; $\mathrm{p}=0.006$ [see Additional file 1]). Subsequent analyses with the Bonferroni test [19] revealed a statistically significant difference in the number of stained motor neurons in spinal cord between the groups that were repaired immediately ( 0 days) and the other three groups where a delayed nerve repair was done (repaired 30, 90 and 180 days post injury). However, the latter three groups were not different from each other with respect to number of ATF3 stained motor neurons.
\end{abstract}

\section{Sensory neurons in DRG}

In the contralateral side (uninjured) no sensory neurons stained for ATF3 (Figure 1d). Nerve transection and repair induced differences in number of ATF3 stained sensory neurons in DRG between the different groups of immediate and delayed nerve repair (Kruskal Wallis; $\mathrm{p}=0.003$; Figure $1 \mathrm{e}-\mathrm{h}$ ). There was a statistically (Bonferroni test) higher number of stained neurons after immediate repair and repair 30 days after injury than after a delayed repair at 90 and 180 days after transection [see Additional file 1].

\section{Non-neuronal cells (i.e. Schwann cells)}

The number of non-neuronal Schwann cells was evaluated at four locations (two shown in Figure 2a). The majority of the non-neuronal cells in the proximal (two sites; results not shown) and in the distal nerve segment (SND; Figure 2a) and at the site of the lesions (SNL; Figure 2a) had the characteristics of Schwann cells. They stained for S-100 and were defined as Schwann cells based on morphological characteristics (shape of nucleus and loca- 
tion within basal lamina) in accordance with previous studies [16]. The contralateral uninjured side showed no or only single ATF3 stained cells (Figure 2h).

Schwann cells at site of nerve lesion (SND)

There was a significant difference between the nerves repaired at different time points after injury with respect to ATF3 stained Schwann cells just distal to the site of nerve lesion (SNL; Figure 2a; Kruskal Wallis; $\mathrm{p}=0.02$ ). The number of ATF3 stained Schwann cells were significantly higher (Bonferroni test [see Additional file 1]) after immediate repair and repair 30 days after transection than in nerves repaired 90 and 180 days after transection (Figure $2 b, d, f)$.

\section{Schwann cells in distal nerve segment (SND)}

There was a significant difference in ATF3 stained Schwann cells in the nerve segment $15 \mathrm{~mm}$ distal to the sutured lesion (SND; Figure 2a; Kruskal Wallis; $\mathrm{p}=0.02$ ). The statistical analysis (Bonferroni test) showed significant changes with the same pattern as at the site of nerve lesion (SNL). Thus, after immediate repair (Figure $2 \mathrm{c}$ ) and repair 30 days post transection (Figure $2 \mathrm{e}$ ) a significantly higher numbers of ATF3 stained Schwann cells were observed in the distal nerve segment (Bonferroni test [see Additional file 1]) than in the corresponding nerve segment when the nerve trunk was repaired 90 (Figure 2g) and 180 days (Figure 2i) after transection.

\section{Total number of DAPI stained cells in distal nerve segment}

The total number of DAPI stained cells (not only, but mainly, Schwann cells; S100 staining) in the distal nerve segment (SND; Figure 2a) was higher than in the contralateral control nerve at all time points (Mann Whitney; $\mathrm{p}<$ $0.05)$. There was also a significantly higher total number of DAPI stained cells in the distal nerve segment when repair was done with a delay of 180 days than after immediate ( 0 days) and a delay of 30 days (Kruskal Wallis; $\mathrm{p}=$ 0.016; subsequent Bonferroni test [see Additional file 1]).

\section{Length of axonal outgrowth}

The outgrowth length from the site of nerve repair into the distal nerve segment was judged by neurofilament staining. There was a significant difference (Kruskal Wallis $\mathrm{p}=$ 0.002 [see Additional file 1]) between the groups of immediate and delayed nerve repair. The outgrowth lengths in nerves repaired immediately ( 0 days) or 30 days after transection were significantly longer (Bonferroni test [see Additional file 1]) than in nerves repaired 90 and 180 days after transection (no difference between the latter two). Double labelling with anti-ATF3 and anti-neurofilament antibodies showed that axons frequently grow along ATF3 stained Schwann cells (elongated nucleus in basal lamina and stained for S-100; [16]) in the distal nerve segment (Fig. 3a, b).

\section{Neural cell adhesion molecule (NCAM) in the repaired sciatic nerve}

Staining for NCAM was used to visualise non-myelinating Schwann cells [18]. NCAM and neurofilament doublestaining were analysed in longitudinal sections both at the site of the lesion and in the distal nerve segment. In contralateral control nerves only patchy areas of NCAM staining were seen and large diameter nerve fibres were not associated with NCAM (Figure 3c). In ten days after transection and immediate repair neurofilament stained fibres with positive NCAM staining had increased, but fibres not associated with NCAM were still seen (Figure $3 \mathrm{~d}$ ). When the repair was delayed 30 (Figure 3e), 90 (Figure $3 \mathrm{f}$ ) or 180 days after transection almost all regenerating neurofilament stained fibres were associated with NCAM positive staining, although the number of regenerating nerve fibres was reduced at the latter two time points. Thus, the majority of regenerating nerve fibres after delayed nerve repair were associated with non-myelinating Schwann cells (NCAM stained; $[18,20]$ ).

\section{Correlation}

The Spearman correlation test revealed a significant correlation between length of axonal outgrowth and the number of ATF3 stained motor neurons (Rho $=0.69, \mathrm{p}=$ 0.005 ), ATF3 stained sensory neurons (Rho $=0.77, \mathrm{p}=$ $0.002)$, and in the distal nerve segments [site of lesion $(\mathrm{SNL})$; Rho $=0.76, \mathrm{p}=0.001$; nerve segment $15 \mathrm{~mm}$ distal to lesion; SND; Rho $=0.71, \mathrm{p}=0.003$ ] when all groups were included. The number of ATF3 stained Schwann cells at the two sites in the proximal nerve segment did not correlate to axonal outgrowth.

The number of ATF3 stained sensory neurons in DRG correlated also to the number of ATF3 stained motor neurons (Rho $=0.68, \mathrm{p}=0.007$ ) and number of ATF3 stained Schwann cells in the distal nerve segment (Rho $=0.71, \mathrm{p}$ $=0.003$ ) when all groups were included. Furthermore, there was a significant correlation between number of ATF3 stained motor neurons and Schwann cells in the distal nerve segment (Rho $=0.48, \mathrm{p}=0.042$ ).

\section{Discussion}

ATF3 is a member of the CREB family and its rapid expression after injury in neurons is preceded by a fast upregulation of JNK and phophorylation of c-jun $[12,13,16]$. Sensory and motor neurons [13] and non-neuronal cells (i.e. Schwann cells; [14]) in the injured nerve trunk showed a decline in ATF3 response after transection and delayed nerve repair. The reduction of ATF3 stained neurons and Schwann cells correlated to axonal outgrowth. ATF3 expression is long lasting in sensory, but not in motor, neurons if regeneration is prevented [16]. Progression of axonal outgrowth into the distal nerve segment after a nerve crush decreases the number of ATF3 stained 


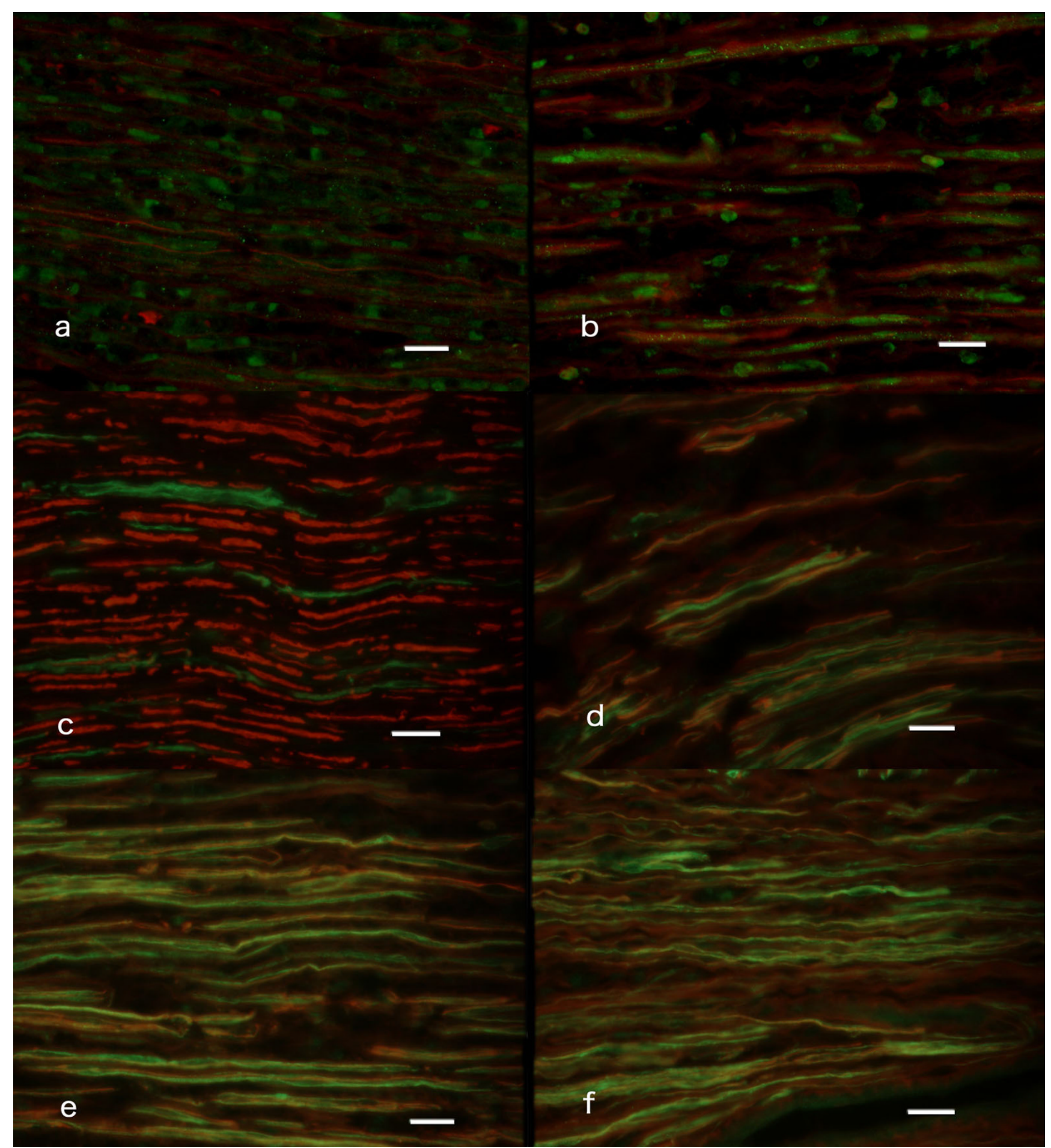

\section{Figure 3}

Images of double labeling of ATF3 and neurofilament (a, b) and NCAM and neurofilaments (c-f). Double immunochemical staining of ATF3 and neurofilaments $(a, b)$ from the distal nerve after immediate repair (day 0 , a) and delayed repair at day 30 (b). Note ATF3 stained Schwann cells close to regenerating fibers. Double immunochemical staining of NCAM (green) and neurofilaments (red) at the contralateral uninjured side (c), at the injured side where sciatic nerve was repaired immediately (d), repaired with delay of 30 days (e) and 90 days (f) after injury. Note the difference in staining of neurofilament and NCAM between c, d, e and f. Scale bar $=50 \mu \mathrm{m}$. 
motor and sensory neurons both with time and with reinnervation indicating a complex regulation [16]. Retransection of the axons at the time of delayed nerve repair, which is necessary for coaptation, may influence expression of ATF3, since the number of ATF3 expressing neurons was lower than that found when a transection was not repaired [16]. ATF3 expression in Schwann cells decreased with time after denervation in the absence of regeneration $[16,17]$. In addition, reinnervation of target gives a more rapid decline of ATF3 expression [16]. Interestingly, the number of ATF3 stained neurons and Schwann cells and length of axonal outgrowth correlated when all groups were examined, indicating that delayed nerve repair influences axonal outgrowth and ATF3 expression in neurons and Schwann cells. Therefore, both neurons and Schwann cells are probably of importance for nerve regeneration in delayed nerve repair. Outgrowing axons were associated with ATF3 stained Schwann cells in the distal nerve segment [14] (Figure 3). One may suggest from our and other studies that ATF3 expression in Schwann cells is important for the support of regeneration [14]. As previously shown, ATF3 in neurons promotes neuronal survival and neurite outgrowth, particularly of sensory neurons in DRG [15,21-23]. In addition, inhibition of JNK, and thereby ATF3, reduces outgrowth of sensory axons [12]. We found a correlation between the number of ATF3 expressing neurons and axonal outgrowth. No data are available for a connection between the expression of ATF3 and the regeneration of motor fibers. However, the number of stained motor neurons in the spinal cord correlated with regeneration distances of axons, indicating that not only sensory [21,23], but also motor neurons may be dependent on ATF3 for survival and outgrowth after delayed nerve repair. In the spinal cord, the number of ATF3 stained motor neurons decreased significantly between immediate repair and a repair with a delay of 30 days. Interestingly, the decrease was faster if the nerve was repaired, as in the present study, compared to previous studies when regeneration was not permitted [16], signifying that expression of ATF3 in motor neurons is dependent on interaction between motor neurons and Schwann cells. One may also suggest that early nerve repair is more important for motor neurons than for sensory neurons [24,25], particularly with respect to non-myelinated fibers, as there is better functional motor recovery after early repair [26,27].

The number of ATF3 stained sensory neurons, and the length of outgrowing axons decreased between groups with a repair delay of 30 and 90 days. Neurofilament stained axons were only partly associated with NCAM stained areas of Schwann cells after immediate repair, while after repair at 90 and 180 days post injury almost all regenerating nerve fibers were associated with NCAM stained Schwann cells (Fig. 3d, e, f). The latter findings point towards a more prominent regeneration of nonmyelinated axons after a delayed nerve repair, since NCAM (and L1) is associated with non-myelinating Schwann cells and not myelinating Schwann cells $[18,20]$. However, we cannot differentiate with certainty between sensory and sympathetic axons by the neurofilament staining. Staining for the adhesion molecule L1 has been claimed to be present in Schwann cells of sympathetic unmyelinated axons [20]. In addition, in clinical practice early nerve reconstruction is more effective than delayed reconstruction in relief of pain after brachial plexus injuries [28]; a factor pointing toward a better regeneration of myelinated axons after early repair.

Non-neuronal cells were also stained by ATF3 antibody $[13,14]$, the majority being Schwann cells (characteristics: elongated nucleus, located within basal lamina and S-100 positive) $[14,16,29]$. Expression of ATF3 in Schwann cells has been seen rapidly after nerve injury $[13,14,16,29]$, but was significantly decreased if repair was delayed for more than 30 days. Although the total number of DAPI stained (mostly, but not only, Schwann cells) cells in the distal nerve segment increased significantly when the nerve was repaired 180 days after injury, compared to the other groups, only around $13 \%$ of the Schwann cells stained for ATF3. Double staining of ATF3 stained Schwann cells and neurofilaments in the distal nerve segment (Figure 3) showed a close relationship; but the suggestion that ATF3 may be important for differentiation of Schwann cells, myelination and regeneration $[21,30]$ has to be proven. ATF3 stained Schwann cells were also seen where there were no regenerating fibers in the distal nerve segment, signifying that contact with regenerating nerve fibers is not completely responsible for the decline in ATF3 in Schwann cells [16].

The distal nerve segment is important for axonal outgrowth, as shown particularly well in experiments using short term predegenerated nerve grafts [9]. ATF3 expression in Schwann cells and Schwann cell proliferation, influenced by Erk1/2 expression [8], occurs in the distal nerve segment within a few days of injury $[13,14,16,29]$. The number of DAPI stained cells (all type of cells; not only, but mostly, Schwann cells) was also higher in the injured side than in the uninjured nerve trunk at all time points. A distal nerve segment denervated for a prolonged period looses its ability to induce and properly support regeneration $[5,31,32]$. Schwann cells express many regeneration-associated proteins, such as NGFR/p75, GAP43 and extracellular matrix molecules [30,33]. The synthesis of NGFR/p75 in denervated Schwann cells has a similar time course as ATF3 expression with a peak at one month. NGFR/p75 is barely detectable six months after injury [34]. In addition, c-erbB receptors have been investigated in Schwann cells denervated for up to 6 months in 
vivo $[32,35]$. The levels of c-erbB receptor expression by Schwann cells, and the degree to which axons regenerated into the distal stumps both decreased with an increased period of denervation. Addition of Leukaemia Inhibitory Factor (LIF) can modulate Schwann cell survival and improve recovery of motor function after delayed nerve repair [36], but a clear connection between ATF3 and LIF has not been established $[37,38]$. The number of Schwann cells expressing ATF3 decreased with delayed nerve repair and did not increase after repair when compared with previous data [16]. Schwann cells most probably die in the distal nerve segment with delayed nerve repair (see e.g. $[31,32]$. Thus, nerve repair should be performed as soon as possible to utilise the expression of regeneration associated factors, such as ATF3, in both neurons and Schwann cells.

After nerve injury there is a loss of neurons, particularly in DRG [39-41]. The mechanisms are not completely understood, but ATF3 may determine the cell fate after injury [42-44]. ATF3 as a heterodimer with c-Jun promotes neuronal survival under stress by induction of the anti-apoptotic factor heat shock protein 27 [45]. Inhibition of c-jun activation increases the number of apoptotic sensory neurons after injury in the DRG [22]. Thus, ATF3 plays a role in cell survival and cell cycle. If the present data is compared with previous reports of the decline of ATF3 expression after injury [16], one may suggest that a neuron or a Schwann cell that has lost ATF3 will probably not properly recover their ability to express ATF3 after an additional injury with a diminution of supporting nerve regeneration.

\section{Conclusion}

Delayed nerve repair after an injury impairs the outgrowth of axons in the distal nerve segment. Regeneration distances correlate to the decline of both the number of ATF3 stained neurons and Schwann cells over time. ATF3 stained motor neurons decreased more rapidly than sensory neurons over time. Non-myelinating Schwann cells (NCAM stained) in the distal nerve segment increased when repair was delayed, indicating abundant regeneration of non-myelinated axons after delayed nerve repair. From the neurobiological point of view nerve trunks should, if possible, be promptly repaired.

\section{Methods}

Animals

Twenty Wistar female rats (weight 180-200 g) were anesthetized, after approval of the local Animal Ethics Committee of Lund University, with an intraperitoneal injection of a mixture of sodium pentobarbital $(60 \mathrm{mg} /$ ml, Apoteket AB, Stockholm, Sweden) and sodium chloride $(9 \mathrm{mg} / \mathrm{ml}: 1 / 10, \mathrm{v} / \mathrm{v})$. Adequate measures were taken to minimize pain and discomfort. Experiments were con- ducted in accordance with international standards on animal welfare and compliant with local and national regulations.

\section{Sciatic nerve transection and repair}

The sciatic nerve in the left hind limb was exposed and transected $10 \mathrm{~mm}$ proximal to the branching of the tibial and peroneal nerves. Four different time points were used to study the influence of delay of nerve repair. In one group the nerve was immediately sutured with 9-0 nylon suture with stitches in the epineurium (day $0 ; n=5$ ). In the other groups the distal nerve stump was reversed and put between the muscles at a distance of at least $20 \mathrm{~mm}$ from the proximal one to avoid spontaneous reconnection. The wound was closed and the rats were housed in cages. At day $30(n=5), 90(n=5)$ or $180(n=5)$ after nerve transection, the rats were re-anesthetized and the nerve ends were sutured with application of 9-0 nylon sutures in the epineurium after retransection of both nerve stumps (resection $0.5-1 \mathrm{~mm}$ ) to make coaptation easier. The wound was closed and the rats allowed to recover.

Ten days after nerve repair (i.e. 10, 40, 100 and 190 days after the nerves were transected initially) the rats were killed by an i.p. injection with an overdose of sodium pentobarbital followed by a heart puncture. The sciatic nerves bilaterally, the dorsal root ganglia (DRG; L4 and L5) bilaterally and the lumbar enlargement portion of the spinal cord were removed. The samples were fixed in Stefanini fixative (4\% paraformaldehyde and $1.9 \%$ picric acid in $0.1 \mathrm{M}$ phosphate buffer, $\mathrm{pH}$ 7.2) for two hours. They were washed in $0.01 \mathrm{M}$ PBS (phosphate buffered saline, pH 7.4) and kept in 20\% sucrose in 0.01 M PBS at $4^{\circ} \mathrm{C}$.

\section{ATF3 expression in the sciatic nerve, spinal cord and the dorsal root ganglia (DRG)}

For sectioning the samples were embedded in O.C.T. compound (Sakura Finetek Europe, Leidens, Netherlands) and frozen rapidly in a freezer. The samples were sectioned in a cryostat at $10-\mu \mathrm{m}$ thickness, and mounted on glass slides. The sciatic nerves were sectioned longitudinally and the spinal cords horizontally. In order to investigate expression of ATF3, the sections were stained with anti-ATF3 antibody (see below).

\section{Measurement of axonal outgrowth}

To measure the length of the regenerating nerve fibers, the sciatic nerve sections $(10 \mu \mathrm{m}$ thick) were stained with anti-neurofilament antibody (see below) and visualized by $\mathrm{ABC}$ (Avidin and Biotinylated horseradish peroxidase macromolecular Complex) technique (as detailed below). The slides were photographed using a fluorescence microscope (Eclipse; Nikon, Tokyo, Japan) equipped with a dig- 
ital camera system (Digital Sight, Nikon, Tokyo, Japan) and the length of axonal outgrowth was measured. Some sections of the sciatic nerves were also double-labelled with the anti-ATF3 antibody and the anti-neurofilament antibody to clarify the relationship between regenerating axons and ATF3 positive Schwann cells.

\section{NCAM expression in the sciatic nerve}

In order to visualize the non-myelinating Schwann cells with the regrowing axons, some sections of the sciatic nerves were double-labelled with the anti-NCAM antibody (see below) and anti-neurofilament antibody according to a previous protocol [18].

\section{Immunocytochemistry}

The sections were washed 10 min with PBS $(0.01 \mathrm{M}, \mathrm{pH}$ 7.4) and incubated with the primary antibodies (as detailed below) dissolved in $0.25 \%$ BSA (bovine serum albumin), $0.25 \%$ Triton-X (Packard, Meriden, USA) and in $0.01 \mathrm{M}$ PBS overnight at $4^{\circ} \mathrm{C}$. After washing with PBS, the sections were incubated for 1 hour at room temperature with the secondary antibodies (as detailed below) diluted in PBS. After washing with PBS, the sections were mounted with VECTASHIELD ${ }^{\circledR}$ Mounting Medium with DAPI (4',6-diamino-2-phenylindole) (Vector Laboratories, Burlingame, CA, USA).

\section{$A B C$ technique}

The sections of sciatic nerve were washed 5 min with PBS $(0.01 \mathrm{M}, \mathrm{pH} 7.4)$, and incubated with $0.3 \% \mathrm{H}_{2} \mathrm{O}_{2}$ in methanol for 30 minutes at room temperature. After washing with PBS, the sections were incubated with diluted horse serum for 20 minutes at room temperature followed by incubation with the primary antibody (as detailed below) diluted in PBS for 2 hours at room temperature. After further washing with PBS, sections were incubated with the secondary antibody (as detailed below) with rat serum diluted in PBS. The sections were incubated with VECTASTAIN ${ }^{\circledR}$ ABC Reagent (Vector Laboratories, Burlingame, CA, USA) for 30 minutes at room temperature after a further wash in PBS and later incubation with $10 \mathrm{mg}$ 3-Amino-9-ethylcarbazole (AEC) (SigmaAldrich, St. Louis, MO) dissolved in $50 \mathrm{ml} \mathrm{Na-acetate}$ buffer (0.02 M, pH 5.5) including 1.5 M DMSO (Dimethyl sulfoxide) (Sigma-Aldrich, St. Louis, MO) and 0.3\% $\mathrm{H}_{2} \mathrm{O}_{2}$ for 20 minutes at room temperature. After a final wash with PBS, the sections were stained with Mayers HTX (Histolab Product, Gothenburg, Sweden) and mounted in glycerin.

\section{Antibodies}

The polyclonal rabbit anti-ATF3 antibody (Santa Cruz Biotechnology, CA, USA) was diluted 1:200. The polyclonal mouse anti-neurofilament antibody (Dako, Glostrup, Denmark) was diluted 1:80. The polyclonal rabbit anti-
NCAM antibody (Chemicon, CA, USA) was diluted 1:1000. For immunofluorescence with the anti-ATF3 and anti-NCAM antibodies, Alexa Fluoro 488 conjugated goat anti-rabbit IgG antibody (1:500, Molecular Probes, OR, USA) was used as the secondary antibody. The rhodamine-conjugated anti-mouse IgG (1:500, Cappel, Aurora, OI) was used as the secondary antibody to detect neurofilaments in double immunofluorescence staining. For immunostaining by $\mathrm{ABC}$ technique with the anti-neurofilament antibody, biotinylated horse anti-mouse IgG antibody (1:200, Immunkemi, Stockholm, Sweden) was used as the secondary antibody.

\section{Quantification of number of stained cells}

For examination and quantification of ATF3, the slides were photographed using the fluorescence microscope equipped with the digital camera system as mentioned above. Cell counting was performed on digital images acquired as described [16].

\section{Spinal cord}

Sections of the spinal cord (horizontal section) in every $100 \mu \mathrm{m}$ were analyzed and five sections were randomly selected from the ventral horn for counting ATF3 stained cells [16]. The number of ATF3 stained cells, expressed in percentage of the total number of all neurons with the same characteristics (motor neurons identified based on position, appearance and size in spinal cord), was detected bilaterally. Unstained cells that were larger than the smallest cell, presenting a nucleus, in each section were counted [16].

\section{Dorsal root ganglion (DRG)}

Three sections in every DRG (L4 and L5), each 100-200 $\mu \mathrm{m}$ apart, were randomly selected and sensory neurons, irrespective of size, and exhibiting ATF3 immunoreactivity in their nucleus, were calculated in percentage of the number of neurons with a clear nucleus [16].

\section{Sciatic nerve}

Two sections (100-200 $\mu \mathrm{m}$ apart) from the sciatic nerve were randomly selected and pictures $(500 \times 400 \mu \mathrm{m}$ size $)$ were taken. From these two pictures, areas $[100 \times 100 \mu \mathrm{m}$ $\left.\left(0.01 \mathrm{~mm}^{2}\right)\right]$ were randomly selected for counting. Areas with epineurium/perineurium, large vessels, scar tissue and other non-neuronal tissues were rejected and only the endoneurial space was analyzed. ATF3 stained cells (i.e. Schwann cells; based on appearance of nucleus and location within basal lamina; also stained in some sections for S-100) and DAPI stained cells (including Schwann cells, perineurial cells, fibroblasts, endothelial cells, inflammatory cells and others) in the randomly selected areas were counted. In the operated side, the cells at the distal site adjacent to the sutured site (SNL) and at the $15 \mathrm{~mm}$ distal from sutured site (SND) were quantified (Figure 2a). Cells 
were also counted at two sites $15 \mathrm{~mm}$ proximal to the site of nerve lesion and at the proximal site of the site of repair as well as in the contralateral sciatic nerve (control side).

\section{Statistical methods}

The number of ATF3 stained cells is expressed as median (min-max). Non-parametric methods were used to examine any significant difference between the experimental and control side (Mann-Whitney U-test) and between the experimental side at the four different time points (Kruskal Wallis test with subsequent Bonferroni test; [19]. Spearman correlation test was used to detect any correlations with all animals included. A p-value less than 0.05 is accepted as a significant difference.

\section{Competing interests}

The authors declare that they have no competing interests.

\section{Authors' contributions}

Both authors have contributed equally to the article. Both authors read and approved the final manuscript.

\section{Additional material}

\section{Additional file 1}

ATF stained neurons and Schwann cells, neurofilament stained axons and total number of cells after transection and immediate or delayed nerve repair. Number of ATF3 stained neurons (\% of total number) and Schwann cells (\% of total number), neurofilament stained axons (regeneration distance; $\mathrm{mm}$ ) and total number of cells (DAPI stained) in distal nerve segment after sciatic nerve transection and repair immediately or after a delayed nerve repair (repair 30,90 and 180 days after injury). Evaluation with immunochemistry was done 10 days after the nerve repair.

Click here for file

[http://www.biomedcentral.com/content/supplementary/14712202-9-88-S1.doc]

\section{Acknowledgements}

The project was supported by grants from the Swedish Research Council (Medicine), Crafoord's Fund for Medical Research, Konsul Thure Carlsson Fund for Medical Research, Region Skåne and Funds from the University Hospital Malmö, Sweden.

\section{References}

I. Richardson PM: Recovery of biceps function after delayed repair for brachial plexus injury. J Trauma 1997, 42:79|-792.

2. Samii A, Carvalho GA, Samii M: Brachial plexus injury: factors affecting functional outcome in spinal accessory nerve transfer for the restoration of elbow flexion. J Neurosurg 2003, 98:307-3।2.

3. Samii M, Carvalho GA, Nikkhah G, Penkert G: Surgical reconstruction of the musculocutaneous nerve in traumatic brachial plexus injuries. J Neurosurg 1997, 87:88I-886.

4. Roganovic Z, llic S, Savic M: Radial nerve repair using an autologous denatured muscle graft: comparison with outcomes of nerve graft repair. Acta Neurochir (Wien) 2007, 149:1033-1038. discussion 1038-1039
5. Sulaiman OA, Midha R, Munro CA, Matsuyama T, Al-Majed A, Gordon T: Chronic Schwann cell denervation and the presence of a sensory nerve reduce motor axonal regeneration. Exp Neurol 2002, 1 76:342-354.

6. Midha R, Munro CA, Chan S, Nitising A, Xu QG, Gordon T: Regeneration into protected and chronically denervated peripheral nerve stumps. Neurosurgery 2005, 57:|289-|299. discussion 1289-1299

7. Gordon T, Fu SY: Long-term response to nerve injury. Adv Neurol 1997, 72:185-199.

8. Martensson L, Gustavsson P, Dahlin LB, Kanje M: Activation of extracellular-signal-regulated kinase- $I / 2$ precedes and is required for injury-induced Schwann cell proliferation. Neuroreport 2007, 18:957-961.

9. Kerns JM, Danielsen N, Holmquist B, Kanje M, Lundborg G: The influence of predegeneration on regeneration through peripheral nerve grafts in the rat. Exp Neurol 1993, 122:28-36.

10. Fu SY, Gordon T: The cellular and molecular basis of peripheral nerve regeneration. Mol Neurobiol 1997, I 4:67-II6.

II. Hall SM: The effect of inhibiting Schwann cell mitosis on the re-innervation of acellular autografts in the peripheral nervous system of the mouse. Neuropathol Appl Neurobiol 1986, I 2:40|-4|4.

12. Lindwall C, Dahlin L, Lundborg G, Kanje M: Inhibition of c-Jun phosphorylation reduces axonal outgrowth of adult rat nodose ganglia and dorsal root ganglia sensory neurons. Mol Cell Neurosci 2004, 27:267-279.

13. Tsujino $\mathrm{H}$, Kondo E, Fukuoka T, Dai Y, Tokunaga A, Miki K, Yonenobu K, Ochi T, Noguchi K: Activating transcription factor 3 (ATF3) induction by axotomy in sensory and motoneurons: A novel neuronal marker of nerve injury. Mol Cell Neurosci 2000, 15:170-182.

14. Hunt DA, Hossain-lbrahim K, Mason MR, Coffin RS, Lieberman AR, Winterbottom J, Anderson PN: ATF3 upregulation in glia during Wallerian degeneration: differential expression in peripheral nerves and CNS white matter. BMC Neurosci 2004, 5:9.

15. Pearson AG, Gray CW, Pearson JF, Greenwood JM, During MJ, Dragunow M: ATF3 enhances c-Jun-mediated neurite sprouting. Brain Res Mol Brain Res 2003, I 20:38-45.

16. Kataoka K, Kanje M, Dahlin LB: Induction of activating transcription factor 3 after different sciatic nerve injuries in adult rats. Scand J Plast Reconstr Surg Hand Surg 2007, 4I:158-166.

17. Zigmond RE, Vaccariello SA: Activating transcription factor 3 immunoreactivity identifies small populations of axotomized neurons in rat cervical sympathetic ganglia after transection of the preganglionic cervical sympathetic trunk. Brain Res 2007, I 159:1 19-123.

18. Saito H, Nakao Y, Takayama S, Toyama Y, Asou H: Specific expression of an HNK-I carbohydrate epitope and NCAM on femoral nerve Schwann cells in mice. Neurosci Res 2005, 53:314-322.

19. Stromberg T, Dahlin LB, Lundborg G: Vibrotactile sense in the hand-arm vibration syndrome. Scand J Work Environ Health 1998, 24:495-502.

20. Haney CA, Sahenk Z, Li C, Lemmon VP, Roder J, Trapp BD: Heterophilic binding of $\mathrm{LI}$ on unmyelinated sensory axons mediates Schwann cell adhesion and is required for axonal survival. J Cell Biol I999, I 46: I I73-I I84.

21. Seijffers R, Allchorne AJ, Woolf CJ: The transcription factor ATF3 promotes neurite outgrowth. Mol Cell Neurosci 2006, 32:143-154.

22. Lindwall C, Kanje M: The Janus role of c-Jun: cell death versus survival and regeneration of neonatal sympathetic and sensory neurons. Exp Neurol 2005, 196:184-194.

23. Seijffers R, Mills $C D$, Woolf CJ: ATF3 increases the intrinsic growth state of DRG neurons to enhance peripheral nerve regeneration. J Neurosci 2007, 27:79|I-7920.

24. Jivan S, Novikova LN, Wiberg M, Novikov LN: The effects of delayed nerve repair on neuronal survival and axonal regeneration after seventh cervical spinal nerve axotomy in adult rats. Exp Brain Res 2005: I-10.

25. Kay S, Jivan S, Wiberg M: Influence of pre-surgical delay on the functional outcome of brachial plexus injuries. Scandinavian Hand Society Meeting: Longyearbyen, Svalbard, Norway 2006.

26. Birch R, Raji A: Repair of median and ulnar nerves - primary suture is best. J Bone Joint Surg 199I, 73B:I54-157. 
27. Brunetti O, Magni F, Pazzaglia U: Neural nature of the timedependent factor(s) involved in motor reinnervation. Exp Neurol 1985, 90:677-683.

28. Kato N, Htut M, Taggart M, Carlstedt T, Birch R: The effects of operative delay on the relief of neuropathic pain after injury to the brachial plexus: a review of 148 cases. J Bone Joint Surg 2006, 88B:756-759.

29. Isacsson $A$, Kanje $M$, Dahlin LB: Induction of the transcription factor ATF3 by peripheral nerve compression. Scand J Plast Reconstr Surg Hand Surg 2005, 39:65-72.

30. Scherer SS, Salzer JL: Axon-Schwann cell interactions during peripheral nerve degeneration and regeneration. In Glial cell development 2nd edition. Edited by: Jessen KR, Richardson WD. New York: Oxford University Press; 2001:299-330.

3I. Fu SY, Gordon T: Contributing factors to poor functional recovery after delayed nerve repair: prolonged denervation. J Neurosci 1995, I 5:3886-3895.

32. Hall SM: The biology of chronically denervated Schwann cells. Ann N Y Acad Sci 1999, 883:21 5-233.

33. Li H, Wigley $\mathrm{C}$, Hall SM: Chronically denervated rat Schwann cells respond to GGF in vitro. Glia 1998, 24:290-303.

34. You S, Petrov T, Chung PH, Gordon T: The expression of the low affinity nerve growth factor receptor in long-term denervated Schwann cells. Glia 1997, 20:87-100.

35. Li H, Terenghi G, Hall SM: Effects of delayed re-innervation on the expression of c-erbB receptors by chronically denervated rat Schwann cells in vivo. Glia 1997, 20:333-347.

36. Brown DL, Bennett TM, Dowsing BJ, Hayes A, Abate M, Morrison WA: Immediate and delayed nerve repair: improved muscle mass and function with leukemia inhibitory factor. J Hand Surg 2002, 27A: 1048-1055.

37. Kiryu-Seo S, Kato R, Ogawa T, Nakagomi S, Nagata K, Kiyama H: Neuronal injury-inducible gene is synergistically regulated by ATF3, c-Jun, and STAT3 through the interaction with SpI in damaged neurons. J Biol Chem 2008, 283:6988-6996.

38. Hyatt Sachs H, Schreiber RC, Shoemaker SE, Sabe A, Reed E, Zigmond RE: Activating transcription factor 3 induction in sympathetic neurons after axotomy: response to decreased neurotrophin availability. Neuroscience 2007, I 50:887-897.

39. Tandrup T, Woolf CJ, Coggeshall RE: Delayed loss of small dorsal root ganglion cells after transection of the rat sciatic nerve. J Comp Neurol 2000, 422: I72-I80.

40. Vestergaard S, Tandrup T, Jakobsen J: Effect of permanent axotomy on number and volume of dorsal root ganglion cell bodies. I Comp Neurol 1997, 388:307-3 I2.

4I. McKay Hart A, Brannstrom T, Wiberg M, Terenghi G: Primary sensory neurons and satellite cells after peripheral axotomy in the adult rat: timecourse of cell death and elimination. Exp Brain Res 2002, 142:308-318.

42. Hua B, Tamamori-Adachi M, Luo Y, Tamura K, Morioka M, Fukuda M, Tanaka $Y$, Kitajima S: A splice variant of stress response gene ATF3 counteracts NF-kappaB-dependent anti-apoptosis through inhibiting recruitment of CREB-binding protein/ p300 coactivator. J Biol Chem 2006, 28I: I620-I629.

43. Yan C, Boyd DD: ATF3 regulates the stability of p53: a link to cancer. Cell Cycle 2006, 5:926-929.

44. James CG, Woods A, Underhill TM, Beier F: The transcription factor ATF3 is upregulated during chondrocyte differentiation and represses cyclin $\mathrm{DI}$ and $\mathbf{A}$ gene transcription. $B M C \mathrm{Mol}$ Biol 2006, 7:30.

45. Nakagomi S, Suzuki Y, Namikawa K, Kiryu-Seo S, Kiyama H: Expression of the activating transcription factor 3 prevents c-Jun $\mathbf{N}$ terminal kinase-induced neuronal death by promoting heat shock protein 27 expression and Akt activation. I Neurosci 2003, 23:5187-5196.
Publish with Bio Med Central and every scientist can read your work free of charge

"BioMed Central will be the most significant development for disseminating the results of biomedical research in our lifetime. "

Sir Paul Nurse, Cancer Research UK

Your research papers will be:

- available free of charge to the entire biomedical community

- peer reviewed and published immediately upon acceptance

- cited in PubMed and archived on PubMed Central

- yours - you keep the copyright

Submit your manuscript here:

http://www.biomedcentral.com/info/publishing_adv.asp
BioMedcentral 